\title{
UMA CONVERSA SOBRE ATRAVESSAMENTOS E PACIFICAÇÕES AVÁ GUARANI/ÑANDEVA DE PORTO LINDO (JAKAREY) YVY KATU SOBRE A INVENÇÃO BRANCA DE DESENVOLVIMENTO
}

\author{
Yan Leite Chaparro (UCDB e LabuH) - Email: yanchaparro@gmail.com \\ Joaquim Adiala Hara (Porto Lindo (Jakarey) Yvy Katu) - Email: \\ joaquimguaraninhandeva@yahoo.com.br \\ Josemar de Campos Maciel (UCDB e LabuH) - Email: maciel50334@ yahoo.com.br
}

Resumo: O artigo que segue é um recorte de uma pesquisa de doutorado que tem como objetivo pensar as questões do "desenvolvimento" com os Avá Guarani/Ñandeva do território Porto Lindo (Jakarey) Yvy Katu, situado no sul do Mato Grosso do Sul, a beira do rio Iguatemi no município de Japorã/MS, fronteira como o Paraguai. Pesquisa que compreende os Avá Guarani/Ñandeva como uma sociedade própria que está em simetria com a sociedade capitalista/moderna, em simetria, pois ambas são sociedades que possuem suas cosmologias, organizações sociais, modos de existir e modos de vida. Em simetria, mas que tecem caminhos contrários como organizações que produzem a realidade. Nesse sentido, o recorte apresentado é um conversa reflexiva com um pesquisador Avá Guarani/Ñandeva que permite o levantamento de críticas, inversões e questionamentos sobre o tema ainda em aberto do "desenvolvimento", ou melhor, a invenção branca do desenvolvimento.

Palavras-chave: os Avá Guarani/Ñandeva; Porto Lindo (Jakarey) Yvy Katu; o "desenvolvimento".

Abstract: The following article is a cut from a doctoral research that aims to think about the issues of "development" with the Avá Guarani/Ñandeva, of the territory of Porto Lindo (Jakarey) Yvy Katu, located in the south of Mato Grosso do Sul, on the border of the Iguatemi River in the municipality of Japorã / MS, bordering Paraguay. Research that includes the Guarani / Ñandeva Avá as a society of its own that is in symmetry with modern capitalist society, in symmetry, because both are societies that have their cosmologies, social organizations, modes of existence and ways of life. In symmetry, but that weave opposing ways as organizations that produce reality. In this sense, the clipping presented is a reflexive conversation with a researcher, Avá Guarani / Nandeva, which allows for the raising of criticism, inversions and questions about the still open theme of "development", or rather, the white invention of development.

Key-words: the Avá Guarani/Ñandeva; Porto Lindo (Jakarey) Yvy Katu; the "development". 


\section{Nanduty}

ISSN:2317-8590

\section{Nota introdutória.}

O artigo que segue esta organizado por três momentos: o primeiro momento são as apresentações necessárias que guia a leitura para o segundo e o terceiro momento. Apresenta o dono das palavras guardadas (o pesquisador Avá Guarani/Ñandeva) e o território do qual ressoa as palavras. Já o segundo momento são as palavras que nunca saem de si, como lembra Derrida (1994), palavras produzidas a partir de encontros e conversas sobre o tema do "desenvolvimento. E o terceiro momento são algumas organizações reflexivas a partir das palavras guardadas, que buscam organizar os atravessamentos $\mathrm{e}$ as pacificações sobre $\mathrm{o}$ poder, a invenção branca de desenvolvimento, produzidas pelos Avá Guarani/Ñandeva de Porto Lindo (Jakarey) Yvy Katu.

\section{Apresentações.}

O dono das palavras é o pesquisador Avá Guarani/Ñandeva Joaquim Adiala Hara $^{1}$, que está aqui como um dos autores. Com ele foi possível tecer conversas sobre o tema do "desenvolvimento", pois Joaquim possui um longo trajeto por entre coletivos, discursos e contextos como professor, vereador, secretário da Secretaria de Assistência Social do município de Japorã do Mato Grosso do Sul. Caminhos por entre territórios diferentes que faz potência ao caminhar e ao seu próprio território. Como lembra Clastres (2012) sobre os Últimos Homens.

Potência que está no próprio território que Joaquim Adiala vive e fala, o território Porto Lindo (Jakarey) Yvy Katu, situado no sul do Mato Grosso do Sul, a beira do rio Iguatemi no município de Japorã/MS, fronteira como o Paraguai. Como é possível ver no mapa que segue:

\footnotetext{
${ }^{1}$ Optou-se pelo nome na íntegra do dono da palavra, pela escolha metodológica de pesquisa, que tem como princípio básico o trabalho com o Outro, o que desencadeia um movimento de fazer pesquisa tecido por alianças de trabalho e de amizade.
} 


\section{Nanduty}

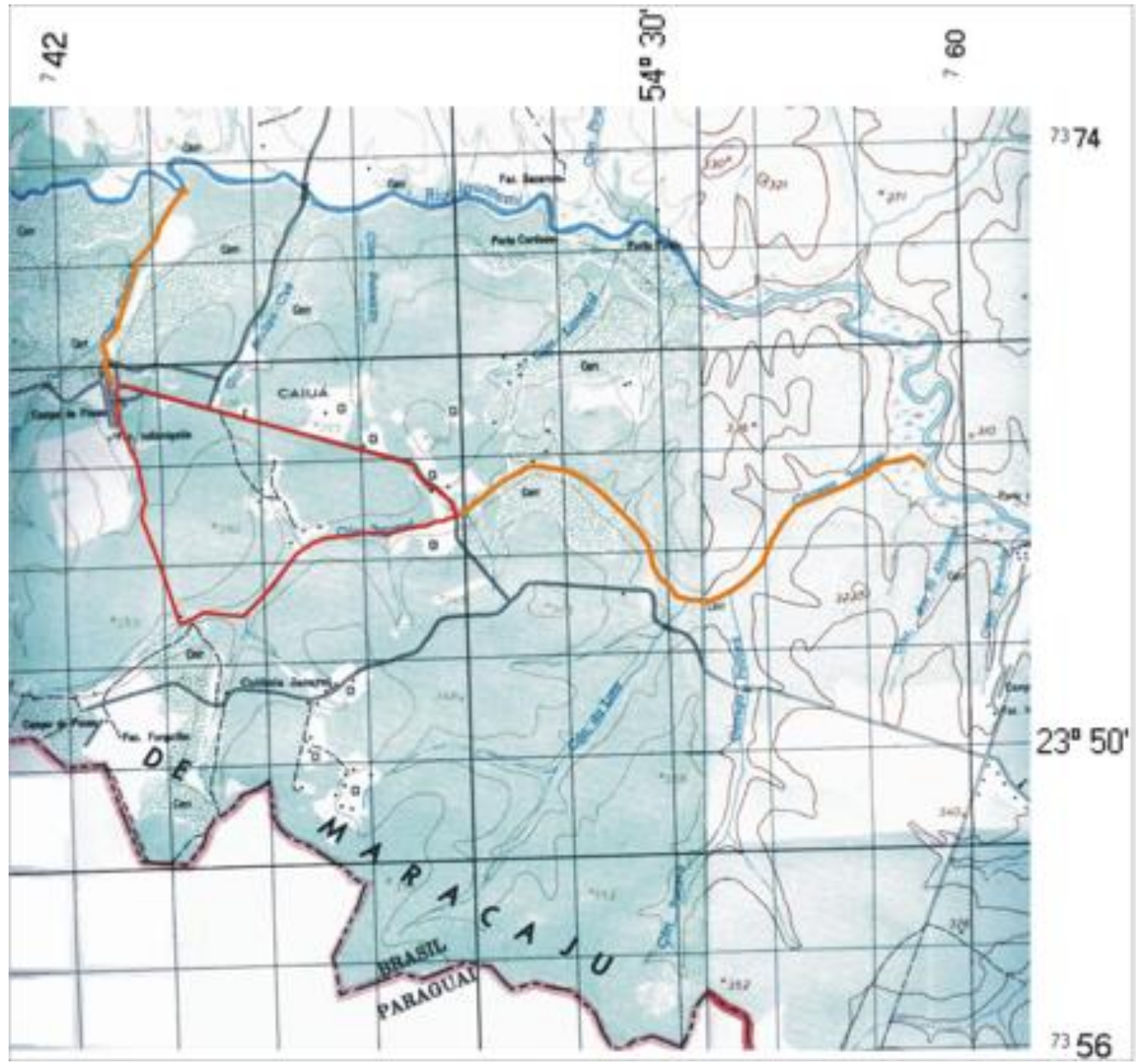

Mapa com a TI Porto Lindo/Jakarey (em vermelho) e a área do tekoha Yvy Katu (em laranja). A porção norte é limite como rio Iguatemi. (LANDA, 2005)

Território descrito da seguinte forma pelo pesquisador Avá Guarani/Ñandeva Eliezer Martins (2011).

Conforme o desenho do mapa hidrográfico de Elias Martins, a divisa desse tekoha começa da nascente Guasori (norte da Aldeia Porto Lindo), que desce até o Rio Iguatemi. Do rio Iguatemi vai descendo até a divisa da Fazenda Remanso e dali vai descendo até a ponta do córrego Jacareí. De acordo com sua fala, nesse espaço viviam oito ou mais famílias grandes que circulavam o tekoha, ou seja, se movimentavam para pescar, caçar, procurar remédios tradicionais, faziam festa da chicha em seus quatro cantos. O mapa hidrográfico localiza os dois córregos e um rio que delimitam o tekoha Yvy Katu: córregos Guasori e Jacareí e o rio Iguatemi. Localizou ainda os pontos limites dentro do município de Japorã - MS. [...] Com o objetivo de explicar melhor 


\section{Nanduty}

ISSN:2317-8590

faço a diferenciação entre a área de Porto Lindo e a de Yvy Katu a partir das informações da liderança Rosalino Ortiz. Após a retomada da área pelos guarani e kaiowá, os rezadores decidiram batizar novamente aquele tekoha. O território já ocupado continuou a ser denominado Porto Lindo. O nome ficou, pois os indígenas em sua maioria trabalhavam no porto e se acostumaram com a denominação dada pelos não indígenas. A terra reconquistada e rebatizada recebeu a denominação de Yvy Katu (Terra Sagrada). Foi assim denominada, pois lá havia o cemitério guarani e kaiowá e locais de reza dessa etnia. [...] YvY Katu divide-se em cinco setores: Larreakue, Paloma, Remanso, Agrolak e a Missão Evangélica Caiuá. Os lugares onde os guarani e kaiowá estabeleceram seus acampamentos receberam o nome das fazendas que estavam dentro dos limites do tekoha. Porto Lindo, por sua vez, possui quatro setores divididos pelos agentes de saúde da Fundação Nacional de Saúde (FUNASA): Bentinho, Guasori, Yú (nascente) e Escola do Alfredo. (2011, p.03)

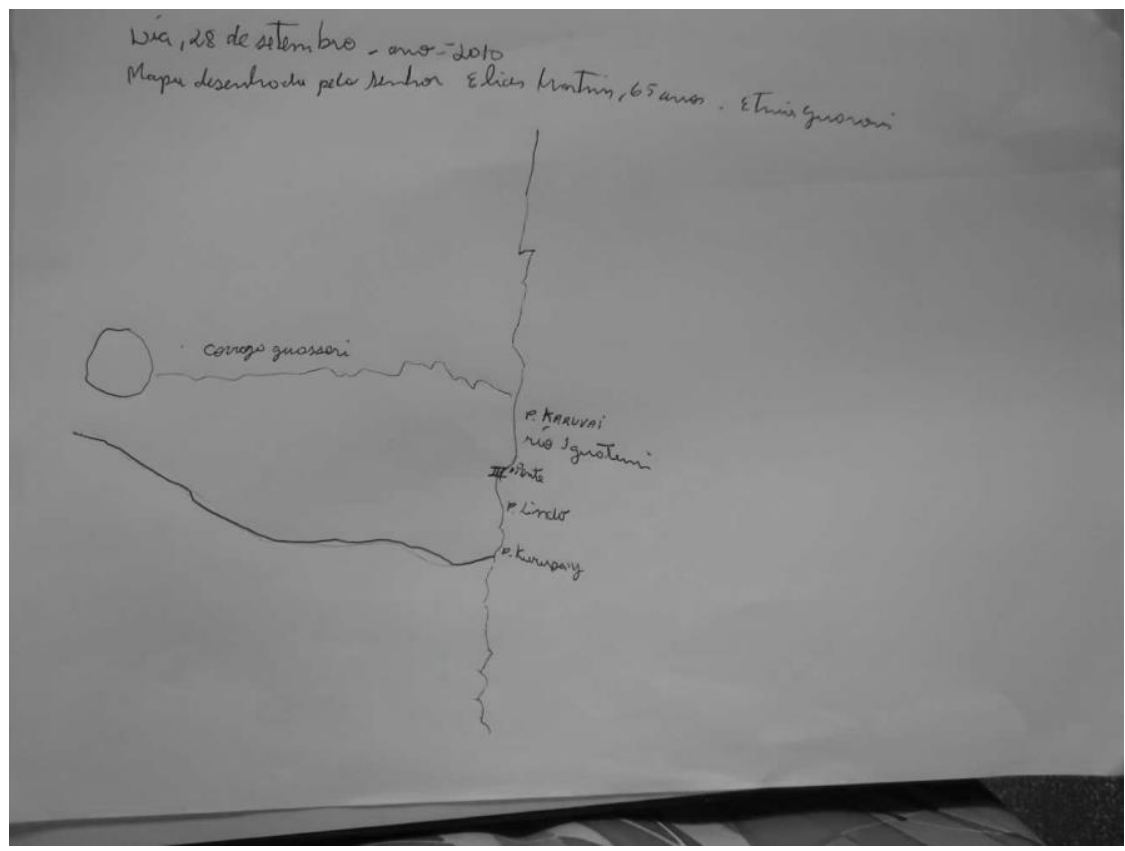

Mapa 1 - Desenhado por Elias Martins no dia 28.09.2010 - Localização dos córregos e rio que limitam a área guarani e kaiowá do município de Japorã-MS. Fonte: Eliezer Martins (2011) 


\section{Nanduty}

Território ocupado hoje por quase cinco mil indígenas em sua maioria Avá Guarani/Ñandeva, existindo também alguns poucos Kaiowá, por volta de 117 pessoas $^{2}$, onde com a retomada de Yvy Kau pode chegar a proposta de ampliação de limites abrangem 9.461,4429 hectares (MURA, 2002), descrito no anterior mapa produzido por Landa (2005) concretizando por fim o grande território Porto Lindo (Jakarey) Yvy Katu.

O que segue são palavras de um pesquisador Avá Guarani/Ñandeva, e reflexões junto com dois pesquisadores não-indígenas. Movimento que se aproxima da possibilidade inscrita por Viveiros de Castro (2015) de Aceitar a oportunidade e a relevância desta tarefa de "penser outrement" (Foucault) o pensamento - de pensar "outramente", pensar outra mente, pensar com outras mentes [...] (p.25). Com o objetivo de tecer uma maior conversa a partir de pequenas conversas e reflexões sobre a questão do "desenvolvimento" para os Avá Guarani/Ñandeva, uma questão que consequentemente produz o fenômeno de reflexividade e vertigem para os mecanismos de poder que busca sempre conduzir os Avá Guarani/Ñandeva a um estrato de domínio perverso. Por isso, a organização textual inscrita aqui utiliza o itálico para as palavras indígenas e o não itálico para as palavras não-indígenas, com o objetivo de identificar os textos sem perder a distância e a diferença.

\section{As palavras ${ }^{3}$}

É Yan, parece que a sociedade moderna que você diz e que você vive, já naturalizou a exploração, os malefícios e as doenças do capitalismo, as pessoas até sabem que o capitalismo, este tal desenvolvimento faz mal, que só traz exploração e malefícios, como as lavouras, os latifúndios, os venenos, as poluições e um jeito de viver doente. Mas, as pessoas já naturalizaram tudo isso, eles até reclamam, mas não fazem nada, eles já incorporaram esse jeito de viver doente, que só traz malefícios.

\footnotetext{
${ }^{2}$ Ver Landa (2005, p. 102)

${ }^{3}$ Palavras de Joaquim Adiala Hara a partir de reflexões e conversas tecidas na cidade de Campo Grande/MS e no território Porto Lindo (Jakarey) Yvy Katu sobre.
} 


\section{Nanduty}

ISSN:2317-8590

E nós, os Avá Guarani/Ñandeva, a gente apreende com os mais velhos e com as lideranças a não naturalizar essas coisas, a gente apreende a se incomodar, a questionar o capitalismo e esse tal desenvolvimento. Por isso, a gente busca nosso território, porque a gente não aceita, se incomoda e questiona este modelo de sociedade capitalista. A gente busca o território por não aceitar o que a sociedade moderna chama de viver. ${ }^{4}$

Você pode escrever sobre isso em uma parte da sua tese. Sobre o não aceitar, o incomodo e os nossos questionamentos, dos Avá Guarani/Ñandeva, sobre a sociedade moderna, capitalista. Que é esse incomodo e esse questionamento que faz a gente caminhar, por não aceitar as verdades do capitalismo. Você poderia escrever sobre esse incomodo nosso. Porque uma pesquisa serve também para indagar e questionar. ${ }^{5}$

Na verdade professor, o desenvolvimento que a gente vê e o que que é desenvolvimento para nós. Os não-indígenas vê a questão de ver tudo como capital, só vê o material, vamos dizer assim. No material que dá lucro, que vai dar lucro para eles, e a terra os não-indígena só vê como capital: a terra, as plantações, a própria natureza, os não-indígenas vê como capital. De um lado o capital traz dinheiro para os não-indígenas e, ao mesmo tempo, traz prejuízo para o meio ambiente, e a gente vê ao contrário; para os não-indígenas o quê vai salvar, o que vai melhor, quanto mais tem capital, quanto mais tem dinheiro melhor para eles e isso traz prejuízo para todos nós, pro indígena e para o não-indígena.

As plantações, mesmo que eles plantam em grande escala, usam muito agrotóxico, usam a terra até ficar sem vida, muitas vezes ficam sem. Usam vários produtos para que possam aumentar a produção e, para nós o desenvolvimento, a gente

\footnotetext{
${ }^{4}$ Palavras de Joaquim que podem ser conhecidas em Pierre Clastres (2014) quando descreve a noção de sujeito e sociedade para as sociedades indígenas da América do Sul [ ...] no es, de hecho, un saber sobre la sociedade y, por lo tanto, exterior a ella [...] Es, necessariamente, el saber de la sociedade misma, saber que le es inmanente y que, como tal, constituye su sustância, su Ser sustancial, lo que ella es. (CLASTRES, p.84). Pois quando Joaquim, Eliezer, Eliel e muito outros que estão nesse trabalho dizem, suas palavras estão como sujeitos substanciais a sociedade que vive, e que também pode tecer criticas a sociedade que sempre chega (moderna/capitalista).

${ }^{5}$ Critica que Joaquim faz a sociedade moderna/capitalista a partir da sociedade que vive. Quando explicita a simetria existente entre ambas sociedades. Sociedades simétricas e contrarias, quando os questionamentos e as indagações exibem o caminho contrario e a diferença entre as sociedades, mas que o Avá Guarani/Ñandeva hoje produzem também um movimento de atravessamento e pacificação. Atravessar e pacificar a sociedade moderna/capitalista para manter a sobrevivência da sociedade dos Avá Guarani/Ñandeva como lembra Taussig (1993) sobre a capacidade de atravessar o terror do colonialismo, hoje o capitalismo, nas terras indígenas na América do Sul.
} 


\section{Nanduty}

ISSN:2317-8590

não vê a terra como capital, nem a natureza, a gente preserva ela e a gente usa ela para nossa sobrevivência, para nossa família.

Os indígenas cuidam da terra. Muitas vezes nós também somos questionados por não-indígenas. Porque que a gente, por exemplo, na retomada, a gente vê que, se um capitalista entrar agora na área de retomada do Yvy Katu, ver os pastos vazios, ver as matas começando a se recuperar e para eles isso é um retrocesso e para nós, a gente preserva isso para ter uma vida melhor no futuro e o desenvolvimento, para nós, é cuidar da natureza, ter o espaço para gente encontrar os remédios naturais, cuidar dos rios, das matas.

Viver bem de acordo com a nossa cultura, viver bem de acordo com o nosso modo de ser, de viver, de preservar a nossa língua, preservar a nossa cultura, o nosso modo de socializar um com o outro. E isso para nós é a sobrevivência. Cuidar um do outro, cuidar da nossa família, cuidar da família do outro. Ficar tranquilo. Mas, ao mesmo tempo, também hoje a gente, como a gente tem bastante contato com os nãoindígenas vem vários fatores externos e muitas vezes o indígena é visto, por exemplo, quem tem uma casa melhor, um carro, uma moto, é visto como o índio desenvolvido né, mas na verdade todos somos desenvolvidos; e muitas vezes a gente se apropria desses bens materiais por necessidade e não porque somos melhor do que o outro ou porque somos mais desenvolvidos do que o outro, porque isso para nós não é desenvolvimento, mas a gente se apropria de uma coisa material do não-indígena por necessidade e a gente vê que, não só aqui na aldeia, mas em várias aldeias, tem vários indígenas que tem carro, tem suas motos, tem escola, tem seus outros meios. Muitas vezes a gente se apropria disso por necessidade.

Por exemplo, a escola: a escola hoje é uma necessidade na aldeia; um posto de saúde é uma necessidade na aldeia; se a gente não tivesse no posto de saúde muitos remédios que os não-indígenas trazem, principalmente a Sesai, a Funasa, as próprias secretarias municipais de saúde que fornecem, com as novas doenças que a gente desconhece, que não é da nossa cultura, que veio através do contato dos não-indígenas, muitas vezes é novo para nós também, então por isso nós somos obrigados a se apropriar desses meios dos não-indígenas: os bens materiais que os não-indígena usam a gente acaba se apropriando disso para nossa sobrevivência. Por conta da realidade de hoje, porque hoje é diferente do que era a 50 e 100 anos atrás. 


\section{Nanduty}

ISSN:2317-8590

Na verdade para mim professor é uma coisa nova, hoje sou secretario de assistência social do município de Japorã/MS, com essa minha ida para a Secretaria, acaba a gente abrindo um outro caminho para que a gente possa ter acesso há alguns meios para ajudar a comunidade, principalmente para pensar o novo modelo de assistência social por exemplo. Porque cada secretaria lá fora tem seu sistema próprio, tem um sistema que não é o nosso. Então a gente acaba entrando nesse sistema, mas também levando nosso sistema, a gente leva nosso sistema para dentro desses sistemas de fora. E aí a gente tenta, muitas vezes, confrontar, existe esse confronto, do nosso sistema e o sistema dos não-indígenas.

Então nesse meio existe esse conflito e a gente acha um meio para, como se diz, de negociações, muitas vezes, principalmente, na parte burocrática, pra gente atender nossa população, nossos parentes que chega lá, e também os não-indígenas. Como estou na secretaria, eu envolvo as equipes técnicas dentro no contexto indígena; eles têm que conhecer a realidade da aldeia, a realidade das famílias, de atendimento. Precisam respeitar o sistema indígena para poder atender a aldeia.

A gente esta tentando construir um assistência social indígena. Eu sei que muitas vezes é uma coisa, é uma coisa nova para nossa população; às vezes quando a gente traz alguma coisa para a população, o indígena também estranha isso. Esse primeiro ano meu na secretaria foi um aprendizado muito grande e aí a gente tem que entender, primeiro a gente tem que se apropriar um pouco do sistema dos nãoindígenas, pois nós já temos nosso sistema e levar esse sistema para que eles possam conhecer e a grande maioria, a maioria deles, principalmente os técnicos, não estão preparados para trabalhar com a população indígena.

Não conhecem a realidade nossa, então eles têm que interagir, tem que vim mais pra aldeia, e é isso que a gente tenta fazer. Então tem vários programas, vários projetos dentro do sistema SUAS que podem ser incluídas a população indígena e, mas muitas vezes o sistema não aceita. E a gente tem que achar um meio para que a população indígena seja não enquadrada, mas tenha participação dentro do sistema.

Há um conflito muito grande quando o indígena vai para uma gestão que é pública e que atende toda a população do município indígena e não-indígena, de início para mim foi conflituoso, porque muitas vezes os próprios técnicos não querem aceitar o indígena que esteja na gestão, porque muitas vezes eles acham que sabem tudo sobre 


\section{Nanduty}

ISSN:2317-8590

o sistema, eles acham que tem que ser naquele caminho, tem que impor aquele sistema, e a gente tem esse conflito, entramos em conflito com os técnicos que, para população indígena, têm que ser diferente.

Mas enfim, a gente tenta romper esse modelo dos não-indígenas, tenta levar um novo modelo. Principalmente, eu falo sempre para a equipe, que na secretaria, cada técnico tem o seu papel, mas o papel do individualismo, do trabalho individual; cada um quer trabalhar do jeito dele não quer colaborar um com outro, mas eu tento sempre falar pro pessoal que a gente tem que trabalhar em coletivo: ajudar um ao outro, entender o trabalho do outro, dá a mão para o trabalho do outro, então eu espero assim, que quando estiver na gestão, possa melhorar esse sistema, entre eles também, voltado pra própria equipe, porque o sistema dos não-indígenas é muito individual, muito individual e muitas vezes há muitos conflitos entre eles, isso que eu vejo, e se tiver mais colaboração, mais papel da coletividade eu acho que melhoraria bastante o trabalho dentro da secretaria, não só para a população indígena, mas também como a população não-indígena.

Eu vejo assim, que tem coisas que os não-indígenas, no trabalho que estou agora, tem vários programas, que são os benefícios, vou citar uma delas, alguns beneficios que a secretaria fornece para as famílias mais carentes, para os indígenas $e$ para os não-indígenas, e isso traz muitas vezes dependências. E essa dependência é um malefício, que eu entendo e, por exemplo, o capitalismo também é um malefício: traz. benefício, mas é uma corrente, é uma bola de neve; quanto mais você tem um pouquinho aqui, daqui um mês você quer aumentar isso ou fica dependente disso, e isso para mim é um malefício. Mas os benefícios que a gente se apropria dela é para o mínimo, que muitas vezes não traz nem benefícios, e acaba gerando mais problemas para comunidade. E a gente tem que mudar o pensamento, o modo de andar com esses projetos.

Mas assim, porque você perguntou das matas, então as matas a gente aqui na aldeia Porto Lindo tem pouco, mas na área de retomada tem uma boa parte dela, é grande ainda as matas e a gente preserva ela para que a gente, futuramente, porque tem muitas coisas aqui na aldeia Porto Lindo que a gente encontra os remédios, nas matas, os animais que muitas vezes a gente utiliza como alimento, mas também a gente utiliza como remédios naturais; então a importância da mata é nesse sentido. Muitas 


\section{Nanduty}

ISSN:2317-8590

coisas também a gente retira da mata, a erva que a gente usa pro tereré, no chimarrão e a mata também é o espaço onde a gente aprende com os mais velhos; então muitas vezes uma criança, um pai, uma mãe leva uma criança para mostrar onde é que tem remédio, onde que faz armadilha, como um espaço de escola de sobrevivência, na mata, e a água a mesma coisa: água para nós é fundamental. Porque sem água a gente não existe.

Por isso que uma vez eu falei para você que os mais velhos falam sobre o mito da criação, da criação do universo, da criação do homem, da criação dos rios, dos animais, das matas. Por isso que, quando aprendi sobre as vogais em Guarani, que é a palavra "y” a primeira coisa que Deus criou foi o rio, então depois vem "yvy” a terra, é uma corrente, uma ligação, ligado um no outro, não tem separação. É uma célula, mas pra nós a célula é essa: o "y”, a água, "yvy” a terra, "yvyra”, as plantas, as plantas que a gente tem nas matas, e o "yvyru”, ar. Então, se um deles acaba, acaba tudo, acaba tudo e não existe mais vida.

Então a vida para nós, a nossa célula é isso, e o "tata" é muito importante para nós, porque é onde a gente se reúne, se reuni na beira do fogo para gente tomar chimarrão e também os mais velhos repassa para nós os ensinamentos onde um conta para o outro o que sonhou; e esse sonho também é, através do sonho também se ensina e se aprende. Então o "tata" onde a gente se aquece, mas também é um espaço onde a gente, os mais velhos ensinam as gerações, orientam, ensinam através desse fogo.

Hoje em dia a maioria, a maioria não, tem algumas famílias que têm suas, seus, seu fogão a gás, mas mesmo assim continua. Fogo acho que talvez um pouco poderia dizer assim que, o fogo mudou. O tereré hoje é um fogo, porque ao redor do tereré a gente também conversa muito; quando você chega na casa de um parente ele não vai te levar à beira do fogo, mas ele vai dar a cadeira e já vai trazer o tereré. Então o tereré também acaba sendo um novo fogo diria, um novo modelo de fogo onde a gente conversa, compartilha nossas ideias, compartilha, conta nossa história, conta as novidades, e em várias reuniões que eu já participei com as lideranças, acontece através do tereré. Então o tereré hoje em dia se torna também um fogo. Que antigamente era mais fogo do que o próprio tereré. Porque sem o terere a conversa não tem graça. 


\section{Nanduty}

ISSN:2317-8590

E o território, a área retomada é uma área nossa, muitas vezes os nãoindígenas vê que a retomada do território, e pensa que a gente só quer a terra, mas quando a gente retorna também ressurgem, renascem várias coisas importantes pra nós, a gente retoma outras atividades, outros modos, não é só a terra que a gente recupera, a gente recupera a nossa vida, nossas as práticas pedagógicas dentro do território. Porque é nesse espaço que a gente vai estar aprendendo e vai aprendendo e ensinando. A gente vai esta aprendendo com os mais velhos e ensinando os mais novos a importância do território.

Como a questão da reza, a questão da língua. Quando eu estava nos saberes indígenas, no projeto saberes indígenas, um projeto que foi muito importante para nós professores, na escola, quando eu fui participar, andei bastante lá no Yvy Katu, aí um parceiro falou pra mim assim, para mim visitar ele: vai olhar a minha armadilha. Eu já sabia de algumas armadilhas, mas ele me levou até a armadilha, me mostrou uma armadilha que eu nunca tinha visto. Então eu percebi que naquela ocasião, que aqui não se fazia mais, aqui na Porto Lindo, mas lá consegue fazer aquele tipo de armadilha. É outro tipo de armadilha, então renasce também outro tipo de atividade, outro tipo de meios, outro tipo de, vamos dizer assim, surgem novas atividades, novos ensinos, novas aprendizagens.

\section{O conhecimento como prática que atravessa e pacifica a invenção branca de desenvolvimento.}

Gallois (2008) provoca sem pedir licença o conceito e as questões sobre o desenvolvimento quando esse se aproxima das sociedades indígenas.

Provocador, esse título também se quer ambíguo: quem, afinal, vem atrapalhar o desenvolvimento? Os povos indígenas? Ou, ao contrário, é o desenvolvimento que vem estorvar a vida desses povos? (p. 215)

Indagações que fazem ressonância nas palavras de Joaquim Adiala Hara, pois suas palavras indagam e questionam, produzindo críticas ao conceito de "desenvolvimento", e responde, ainda que inicialmente, as perguntas de Gallois (2008), 


\section{Nanduty}

ISSN:2317-8590

pois esse "desenvolvimento" com todo seu peso de violência, fez e faz violências, mas também pode ser atravessado e pacificado.

Movimento produzido pelos Avá Guarani/Ñandeva no decorrer da história, pois por cima e por de baixo dos seus territórios vemos até hoje marcas da Guerra da Tríplice Aliança, da invasão da Cia Matte Laranjeira e dos projetos do SPI (Serviço de Proteção do Índio) e da CAND (Colônia Agrícola Nacional de Dourados).

Atravessamentos e pacificações que são conhecimentos como prática (BARRETO e SANTOS, p.14, 2015) produzidas por regimes de alteridade de dentro da organização sócio cosmológica Avá Guarani/Ñandeva. Como lembra o também pesquisador Avá Guarani/Ñandeva Eliezer Martins (2018) em uma mesa-redonda no Seminários NEPPI, organizado pelo NEPPI (Núcleo Estudos e Pesquisas das Populações Indígenas) e pelo LabuH (Laboratório de Humanidades/UCDB), que aconteceu no dia 23 de março de 2018 na Universidade Católica Dom Bosco/UCDB.

Somos igual a flores, cada flor é diferente. E o que é melhor, um lugar com varias flores diferente, ou um lugar com só um tipo de flor? Um Brasil com só uma flor, ou com várias flores diferentes. Nós os Guarani sempre nos deparamos com varias culturas diferentes. No nosso território circula muitas culturas diferentes, mas isso não é um problema, pois essas culturas nos ajudam, quando ficamos com as coisas boas delas. O problema é quando algumas culturas chegam com o objetivo de destruir nossa cultura, como quando aconteceu com a Matte Laranjeiras, o confinamento, a escola e a entrada de algumas igrejas. Sempre soubemos lidar com a circulação de varias culturas pelo nosso território, até hoje. Mas, também existem até hoje, políticas de poder que o objetivo é destruir os Guarani, e isso a gente luta contra. Uma estratégia nossa desde muito tempo é parecer que estamos em silêncio. No nosso território aconteceu a guerra da tríplice aliança, a gente não podia lutar de frente, porque íamos ser exterminados. Depois uma avalanche de coisas aconteceu, como a entrada da Matte Laranjeira e o processo de confinamento, e a gente também fez que estávamos em silêncio, e sempre permanecendo no nosso territórios, pois sempre soubemos qual é nosso território. O silêncio sempre foi uma estratégia de sobrevivência, mas hoje a gente não precisa ficar mais em silêncio, por isso retomamos nosso território que foi tirado da gente, e lutamos por políticas e ações que estejam de acordo com o nossa 


\section{Nanduty}

ISSN:2317-8590

cultura, o nosso modo de ser Guarani. O silêncio ajudou a gente a permanecer Guarani, e agora é a luta pelo território, por uma educação indígena, uma saúde indígena, por políticas indígenas e pela escuta dos mais velhos (rezadores) que faz a gente permanecer Guarani. (Eliezer Martins, 2018)

Palavras que faz lembrar a ideia de Micheal Taussig (1993) que devemos pensar-através-do-terror (p.27). E isso que Eliezer Martins e Joaquim Adiala apresentam, pois suas palavras são conhecimentos como prática que atravessam e pacificam o terror, ou melhor, a invenção branca de desenvolvimento, que transita pelos seus territórios historicamente, hoje e ontem. Movimento que fez e faz os Avá Guarani/Ñandeva permanecerem quem são, seus humanos e não-humanos, deslocando vertigens e mecanismos, questionando e transformando esse Outro que sempre chega, assumindo vestimentas sempre de verdade e violência. Pois, esse Outro, sempre mais um que chega, está embasado na maioria das vezes por um projeto ou plano de "desenvolvimento". Mesmo sendo uma guerra ou um empreendimento de Estado ou privado.

Dessa forma, as palavras dos dois pesquisadores Avá Guarani/Ñandeva, questionam e indagam por dentro da sociedade do (s) desenvolvimento (s) a partir do seu próprio território e pela capacidade Avá Guarani/Nandeva de caminhar por entre territórios. Quando no momento de pensar através do terror, transforma o outro em um outro do outro, refletindo como um espelho, a ilusão hegemônica da gênese mítica da sociedade moderna/capitalista, o "desenvolvimento", uma crença como lembra Furtado (1974) e Rist (2002).

Uma crença que tem por princípio a ausência de alteridade (MACIEL, 2017), que faz o outro como um diferente à sua face, e algo que sempre deve ser impedido de vida. O que faz produzir com naturalização sempre o sequestro e a destruição dos humanos e não-humanos que são diferentes do plano inicial de "desenvolvimento". O que faz entender esse plano como um constante processo de etnocídio (CLASTRES, 2014) em relação as sociedades indígenas.

Mas, que de muitas formas, os Avá Guarani/Ñandeva atravessam e pacificam, produzindo uma série de estratégias e artimanhas, alteridades, que não permite o plano de "desenvolvimento" assumir o poder que acostuma ter nos contextos onde ele é um 


\section{Nanduty}

ISSN:2317-8590

regra incorporada como verdade, mesmo que cause cotidianamente malefícios para os coletivos humanos e não-humanos desses contextos, como lembra o próprio Joaquim Adiala.

Nesse sentido, retomar o território Yvy Katu, citado por Joaquim e Eliezer, para os Avá Guarani/Ñandeva é um movimento contínuo e permanente de manter seu próprio modo de existir, de vida, e de produção de realidade. Pois, nesse caso, "desenvolver" é envolver todos os sentidos concretos que guia e direciona o mantimento da vida, uma constante organização onde está em jogo humanos e nãohumanos que faz essa organização. Organização que tem como a gente central os próprios Avá Guarani/Ñandeva personificado no sentido do Yvy Porã, o guardião da vida no mundo, como lembra Joaquim Adiala. Produzindo um sensível tecido que caminhar contra a invenção branca de desenvolvimento, ou mesmo, contra o terror (TAUSSIG, 1993).

As palavras de Joaquim Adiala endereçam críticas a gênese da sociedade moderna/capitalista, por compreender a partir das palavras dos mais velhos, os fenômenos instalados na sociedade do (s) desenvolvimento (s) que tentam confinar e sequestrar os territórios e os modos de existir dos Avá Guarani/Ñandeva. Quando a partir das palavras dos mais velhos entende que para retomar o território e manter seu modo de existir, precisa antes de tudo combater o modelo de sociedade desenvolvimentista. Combate que se dá pela crítica e pela retomada dos seus territórios. Compreende a produção de violência que os outros produzem, e a violência como maneira de viver desses outros, e se coloca contra essas violências. Busca atravessar o terror construído pela invenção branca de desenvolvimento em seus territórios de ontem e de hoje.

Críticas e reflexões que podem ser ouvidas nas palavras Avá Guarani/Ñandeva inscritas nesse manuscrito, que buscam ouvir os rezadores e os mais velhos para saber como poder caminhar e apreender os conhecimentos que circulam pela base do modo de existir dos Avá Guarani/Ñandeva, pois pelos caminhos que essas palavras atravessam, produzem ações entresistemas atreladas a reais demandas do território Porto Lindo (Jakarey) Yvy Katu, para atravessar e pacificar o outro, tornando-o um dispositivo que realmente é permitido circular pelo território na qual essas palavras vivem. 


\section{Nanduty}

Palavras de dois jovens guerreiros Avá Guarani/Ñandeva que retratam realidades vividas no percorrer deles entre diferentes territórios, por dentro de Porto Lindo (Jakarey) Yvy Katu e por outros muitos diferentes. Pois esses guerreiros caminham por entre territórios diariamente, entre a escola, suas casas, as casas de seus parentes, entre roças, entre as casas de seus companheiros, entre as Oga Pisy, a universidade, entre secretarias municipais, estaduais e federais, entre reuniões internas, entre reuniões nacionais sobre educação, saúde e políticas indígenas, e também entre as cidades vizinhas de Porto Lindo (Jakarey) Yvy Katu onde geralmente são tomados por violências explícitas e silenciosas.

Realidades que desenham fenômenos vividos por uma geração que busca atravessar e pacificar a invenção branca de desenvolvimento e seus mais diversos objetos históricos, onde esses dois pesquisadores Avá Guarani/Ñandeva buscam entrar nas mentes e atravessar esses objetos que fazem hoje parte do cotidiano da maioria dos territórios indígenas no Mato Grosso do Sul. Busca profundamente complexa e densa, que requer uma capacidade de alteridade e pacificação daquilo que historicamente só trouxe a imagem do fim do mundo para seus territórios. Ainda mais em um Mato Grosso do Sul e em um Brasil onde o desconhecimento, a violência e a indiferença em relação às sociedades indígenas é um fenômeno ainda naturalizado e normalizado.

\section{REFERÊNCIAS BIBLIOGRÁFICAS}

ALBERT, Bruce e RAMOS, Alcida. (org). 2002. Pacificando o branco: cosmologias do contato no norte amazônico. Apresentação de Manuela Carneiro da Cunha. São Paulo. Editora Unesp.

BARRETO, João e SANTOS, Gilton. 2015. De peixes e homens: por uma outra antropologia. Les Temps Modernes. Paris.

CLASTRES, Pierre. A Sociedade Contra o Estado. 2012. Tradução de Theo Santiago. São Paulo. Cosac \& Naify.

CLASTRES, Pierre. 2014. Investigaciones en antropologia política. Tradução de Estela Campos. 2014. Barcelona. Gedisa Editora.

DERRIDA, Jacques. 1994. A voz e o fenômeno. Rio de Janeiro. Editora Zahar.

FURTADO, Celso. 1974. O mito do desenvolvimento econômico. Rio de Janeiro. Editora Paz e Terra.

GALLOIS, Dominique. 2008. Quem atrapalha o desenvolvimento? Revista Cadernos de Campo, São Paulo. n. 17. 


\section{Nanduty}

ISSN:2317-8590

LANDA, Beatriz. 2005. Os Ñandeva/Guarani e o uso do espaço na terra indígena Porto Lindo/Jakarey, município de Japorã/MS. Tese de Doutorado em História. PUC/RS.

LATOUR, Bruno. 2008. Jamais Fomos Modernos. 4a. Reimpressão. Tradução de Carlos Irineu da Costa. Rio de Janeiro. Editora 34.

MACIEL, Josemar. 2017. Hospitalidade e desenvolvimento: por uma pequena conversação. Trabalho final de pós-doutorado. São Paulo. Universidade de São Paulo.

MARTINS, Eliezer. e MOURA, Noêmia. 2001. Da perda à luta pela retomada do Tekoha Yvy Katu: o ciclo da erva-mate ao ciclo do soja (1940-2010). Anais VI Seminários Povos Indígenas e Sustentabilidade. Universidade Católica Dom Bosco.

MURA, Fábio. (Coord. Do GT); ALMEIDA, Rubem F.T. 2002. Relatório antropológico de revisão de limites da T.I. Porto Lindo (Jakarey): Terra Indígena YVY KATU. Portaria n. 724/PRES.

RIST, Gilbert. 2012. El desarrollo: historia de una creencia occidental. Madrid. Editora Catarata.

TAUSSIG, Michael. Xamanismo, colonialismo e o homem selvagem: um estudo sobre o terror e a cura. Tradução de Carlos Eugênio Marcondes de Moura.1993. São Paulo. Editora Paz e Terra.

VIVEIROS DE CASTRO, Eduardo. 2015. Metafísicas Canibais: elementos para um antropologia pós-estrutural. São Paulo. Cosac \& Naify. 